\title{
Flere påviste misdannelser i nyrer og urinveier
}

\author{
Sammendrag \\ Bakgrunn. Panoramaet av medfødte \\ misdannelser i nyrer og urinveier kan \\ ha endret seg over tid. \\ Materiale og metode. Data for dia- \\ gnostikk, behandling og resultater ble \\ retrospektivt registrert for barn født \\ i Vestfold, Telemark og Buskerud \\ 1987-2006, med alder 1-21 år på \\ registreringstidspunktet.
}

Resultater. Av 142986 levende fødte hadde 389 (2,7 per 1000$)$ misdannelser i nyrer/urinveier. Prevalensen var høyere for barn født 1997-2006 (241/70 217; 3,4 per 1000$)$ enn 1987-96 (148/72 769; 2,0 per 1000$)$ ( $p<0,001)$. Andelen barn med prenatalt påviste anomalier økte signifikant fra første tiårskohort (35/148; $24 \%)$ til siste (125/241; $52 \%)$ ( $p<0,001)$. Urosepsis forekom hos åtte pasienter 11,1 per $1000)$ i første kohort, og ni (1,3 per 1000 ) i siste. 137 pasienter ( $35 \%$ ) har gjennomgått kirurgiske inngrep, hvorav $68(0,9$ per 1000$)$ født 1987-96 og 69 (1,0 per 1000 ) født 1997-2006. Kronisk nyresvikt forekom hos seks 10,1 per $1000)$ i begge tiårskohorter. Henholdsvis fire $(0,05$ per 1000$)$ og $11(0,16$ per $1000)$ døde i de to kohortene $(p=0,07)$.

Fortolkning. Mer utstrakt prenatal diagnostikk har ført til $69 \% \varnothing k n i n g$ av prevalensen av misdannelser. Antall pasienter behandlet kirurgisk, forekomst av urosepsis, kronisk nyresvikt eller død i populasjonen er uendret. Dette tyder på økt diagnostisering av lettere misdannelser.

\author{
Hans Randby \\ hans.randby@siv.no \\ Alf Meberg \\ Barnesenteret \\ Sykehuset i Vestfold \\ 3103 Tønsberg \\ Hussain A.G. Yassin \\ Line Merete Tveit \\ Barnesenteret \\ Sykehuset Telemark \\ Sara Viksmoen Watle \\ Barnesenteret \\ Sykehuset Buskerud \\ Ole Jørgen Moe \\ Ringerike sykehus
}

Anomalier i nyrer eller urinveier utgjør $10-20 \%$ av alle medfødte misdannelser, og er den vanligste misdannelse som påvises prenatalt $(1,2)$. Alvorlighetsgraden varierer fra letale tilstander (f.eks. dobbeltsidig nyreagenesi) til asymptomatiske (f.eks. lette hydronefroser med spontan tilbakegang). Målet med tidlig diagnose er å optimalisere behandlingen og unngå komplikasjoner. Føtal ultralydscreening gir mulighet for å diagnostisere nyre-/urinveisanomalier. Postnatal antibiotikaprofylakse eller kirurgi kan da startes tidlig. Til tross for bedringer $\mathrm{i}$ denne diagnostikken er det fortsatt barn hvor diagnosen stilles i senere barnealder, ofte etter symptomatisk urinveisinfeksjon. Hensikten med den aktuelle undersøkelsen var å belyse disse forholdene nærmere $\mathrm{i}$ et populasjonsbasert materiale for barn født $\mathrm{i}$ 20-årsperioden 1987-2006 i de tre fylkene Vestfold, Telemark og Buskerud.

\section{Materiale og metode}

Misdannelser i nyrer og/eller urinveier hos barn født i 20-årsperioden 1987-2006 diagnostisert og behandlet ved Sykehuset i Vestfold, Tønsberg, Sykehuset Telemark, Skien, Sykehuset Buskerud, Drammen og Ringerike, hvor mor ved fødselen var bosatt i ett av de tre aktuelle fylkene, ble registrert lokalt ved gjennomgang av pasientjournaler, og data anonymisert. I tillegg ble pasienter hjemmehørende i de tre fylkene, og som døde ved regionsykehuset med tidligere ikke erkjente nyre-/urinveismisdannelser inkludert. Sykehusenes diagnoseregistre ble gjennomsøkt for de aktuelle diagnosekoder (ICD-9 753 og ICD-10 Q60-64). Observasjonstiden er fra minst ett til 21 år (median 11 år). De involverte avdelingene utøver de sykehusbaserte pediatriske helseprogrammene i de tre fylkene. Prosjektet er godkjent av Regional komité for medisinsk og helsefaglig forskningsetikk Sør-Øst, Helsedirektoratet og regionsykehusets personvernombud.

Statistiske analyser ble gjort med Fishers eksakte test og khikvadrattest. En p-verdi $<0,05$ ble ansett å angi statistisk signifikant forskjell mellom grupper.

\section{Resultater}

Av 142986 levende fødte i den aktuelle 20årsperioden hadde 389 (2,7 per 1000$)$ misdannelser i nyrer og/eller urinveier. Det var signifikant flere barn med aktuelle diagnoser født i perioden 1997-2006 (241/70 217; $3,4$ per 1000$)$ i forhold til perioden 1987-97 $(148 / 72769 ; 2,0$ per 1000$)(p<0,001)$.

Misdannelsene ble diagnostisert prenatalt hos 160/389 (41\%). Denne andelen økte signifikant fra barn født i første tiårsperiode $(35 / 148 ; 24 \%)$ til sist fødte tiårskohort (125/ $241 ; 52 \%)(\mathrm{p}<0,001)$. Figur 1 viser prevalensen av misdannelser fordelt på fire femårsperioder. Økningen skyldtes flere prenatalt diagnostiserte tilfeller av hydronefrose, henholdsvis $27(0,4$ per 1000$)$ og $96(1,4$ per $1000) \mathrm{i}$ de to tiårskohortene $(\mathrm{p}<0,001)$. Tabell 1 viser årsakene til at nyre- og urinveismisdannelsene ble diagnostisert.

Av barn med misdannelser i nyrer/urinveier ble $51(13 \%)$ født prematurt $(<37$ ukers svangerskapsalder), og 34 (9\%) hadde lav fødselsvekt $(<2500 \mathrm{~g})$. I totalpopulasjonen forekom prematuritet og lav fødselsvekt sjeldnere, henholdsvis hos $9181 / 142986$ $(6 \%)$ og $6828 / 142986(5 \%)(\mathrm{p}<0,001)$. Andelen gutter i materialet var 241 (62\%).

Tabell 2 viser de ulike misdannelsene som ble registrert. 73 av 235 (31\%) pasienter med hydronefrose hadde dette som isolert funn, dvs. uten andre påviste feil i nyrer eller urinveier. Anomaliene var dobbeltsidige hos 175 (45\%), isolert venstresidige hos

\section{Hovedbudskap}

- Prevalensen av diagnostiserte misdannelser i nyrer og urinveier har økt markert

- Uklare kriterier for diagnosen prenatal hydronefrose medfører overdiagnostisering

- Komplikasjonsfrekvens og behov for kirurgisk behandling har ikke endret seg statistisk signifikant 
$138(35 \%)$ og høyresidige hos $76(20 \%)$ $(\mathrm{p}<0,001)$. Andre assosierte syndromer eller misdannelser utenfor nyrer og urinveier forekom hos $70(18 \%)$ av barna.

Urosepsis forekom hos 17 (4\%), hvorav $12(71 \%)$ var forårsaket av Escherichia coli. Det var ingen signifikant endring i forekomsten av urosepsis i løpet av observasjonsperioden $(8 / 72769(0,11$ per 1000$)$ født 1987-96 og 9/70 217 (0,13 per 1000$)$ født 1997-2006; $p=0,75$ ).

Kirurgiske inngrep for misdannelser $i$ nyrer og/eller urinveier ble gjennomført hos 137 (35\%). Det var ingen endring i antall barn som gjennomgikk slike kirurgiske inngrep født 1997-2006 $(69 ; 1,0$ per 1000$) \mathrm{i}$ forhold til foregående periode 1987-96 (68; $0,9$ per 1000$)(\mathrm{p}=0,80)$. To pasienter ble behandlet med dialyse, og to ble nyretransplantert.

$356(91 \%)$ barn er registrert som friske, mens $12(3 \%)$ har utviklet kronisk nyresvikt og $11(4 \%)$ behandlingstrengende hypertensjon (hvorav seks også har kronisk nyresvikt). 15 pasienter (3\%) er døde. Hos barn født 1987-96 og 1997-2006 forekom kronisk nyresvikt hos seks $(0,1$ per 1000$) \mathrm{i}$ begge kohorter $(p=0,95)$, og henholdsvis fire $(0,05$ per 1000$)$ og $11(0,11$ per 1000$)$ døde $(\mathrm{p}=0,07)$. Tabell 3 angir dødsårsakene $i$ materialet. Hos ni $(60 \%)$ var dødsårsaken knyttet til nyre-/urinveismisdannelsen, og hos seks $(40 \%)$ til andre tilstander. Det ble ikke registrert noe tilfelle med malignitetsutvikling i nyrer eller urinveier i materialet.

\section{Diskusjon}

I denne populasjonsbaserte studien fant vi en prevalens for medfødte misdannelser $\mathrm{i}$ nyrer og urinveier på 2,7 per 1000 levende fødte. I andre studier varierer funnene mel$\operatorname{lom} 1,3$ og 7,4 per $1000(1,3-6)$. Det er betydelige forskjeller $\mathrm{i}$ inklusjonskriterier og inndeling av diagnoser i de forskjellige studiene. Dette er mest trolig forklaringen på forskjellene i prevalens, selv om en reell forskjell mellom studiepopulasjonene ikke kan utelukkes. Prevalensen steg betydelig $(69 \%)$ fra første til siste tiårskohort. Dette var først og fremst forårsaket av økt antall prenatalt diagnostiserte tilstander. For barn født i siste tiårsperiode ble hele $52 \%$ av pasientene postnatalt utredet og diagnostisert på bakgrunn av patologiske forhold hos fosteret påvist ved ultralydscreening. De aller fleste av disse var hydronefroser som ikke trengte kirurgisk behandling (fig 2). Det har over tid både i Norge og andre land vært varierende og til dels uklare kriterier for diagnosen føtal hydronefrose (7-9). Studier angir at $47-63 \%$ av prenatalt påviste hydronefroser er forbigående eller fysiologiske $(10,11)$. Lee og medarbeidere fant i en metaanalyse at risikoen for postnatale patologiske forhold øker med graden av prenatal hydronefrose (7). Barn med antenatal hydronefrose opptil $15 \mathrm{~mm}$ diameter har lav insidens av urinveisinfeksjoner og kirurgiske inngrep, og lav insidens og benignt forløp av vesikoureteral refluks (12). Det er derfor bare behov for ikke-invasiv postnatal oppfølging hos disse, og miksjonsurethrocystografi bør bare utføres ved dilaterte uretre. Et av hovedmotivene for å diagnostisere anomalier prenatalt er å unngå eller begrense symptomer og komplikasjoner postnatalt. Til gjengjeld kan en aggressiv utredningspolitikk føre til overbehandling og unødig engstelse hos foreldrene. Vårt materiale, og ovennevnte studier, tyder på en overdiagnostisering av lettere misdannelser, uten påfølgende komplikasjoner eller behov for behandling.

Barn med medfødte misdannelser i nyrer og urinveier hadde økt forekomst av prematuritet og lav fødselsvekt sammenliknet med totalpopulasjonen. Kase \& Visintainer angir i sitt materiale en dobling av risikoen for prematur fødsel ved renale misdannelser, overensstemmende med våre funn (13). Anomalier generelt er ofte knyttet til økt risiko for prematuritet og lav fødselsvekt uten at årsakene til dette er avklart.

Det var nær dobbelt så mange gutter som piker i materialet, noe som går igjen i andre studier $(6,8,11,14,15)$. Urinveiene hos gutter er embryologisk mer komplekse enn hos piker, med større risiko for feilutvikling. Økt miksjonstrykk hos guttefostre kan gi vesikoureteral refluks, hydronefrose og cystisk dysplasi $(11,16)$.

Panoramaet av urinveismisdannelser var preget av tilstander med dilatasjon og/eller obstruksjon i urinveiene. Vi har i vår undersøkelse tatt med alle misdannelsesdiagnoser for hver pasient, selv om noen kan være en følge av andre (f.eks. obstruksjon med dilatasjon av urinveiene proksimalt for obstruksjonen). Fordelingen av diagnoser i vårt materiale er likevel mye lik den $\mathrm{i}$ andre studier $(4,8,10,11,14,15)$. Dominansen av venstresidige anomalier, når disse forekom ensidig, er også funnet av andre, uten at man kjenner noen sikker årsak (10). Dette gjaldt $i$ vårt materiale vesentlig overgangsstenoser. $\mathrm{Ca}$. en tredel av hydronefrosene var en isolert anomali, som har en god prognose for spontan tilbakegang.

Syndromer og misdannelser utenfor nyrer og urinveier forekom $\mathrm{i}$ vårt materiale hos $18 \%$. Det er i andre studier angitt en forekomst av syndromer og assosierte misdannelser hos opptil $30 \%$ av barna $(17,18)$. Påvisning av anomalier i nyrer og urinveier må derfor lede til en bred vurdering av barnet med tanke på om disse kan være ledd i mer omfattende utviklingsavvik.

Tidlig diagnose gir mulighet for tidlig profylaktisk antibiotikabehandling for å hindre infeksjoner og progredierende nyresvikt. Nytten av slik profylakse er imidlertid omdiskutert $(7,11)$. Også tidlig korrigerende operative inngrep har som mål å hindre infeksjoner og progredierende nyresvikt. $A v$ våre pasienter gjennomgikk vel en tredel ulike kirurgiske inngrep. For andre total-

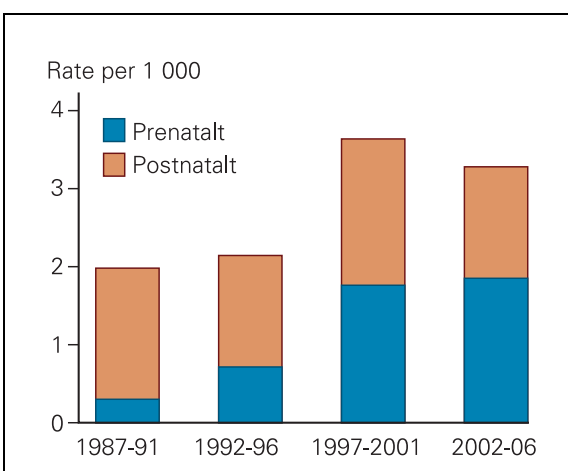

Figur 1 Prevalensen av misdannelser i nyrer og urinveier hos barn født i 20-årsperioden 1987-2006 fordelt på pre-og postnatalt diagnostiserte

populasjoner angis tall forenlig med våre (14). Det var i den aktuelle 20-årsperioden ingen signifikant endring i forekomsten av urosepsis, antall pasienter som utviklet kro-

Tabell 1 Årsaker til diagnose av misdannelser i nyrer og urinveier hos 389 barn

\section{Årsak} Antall $[\%]$

Prenatal ultralydundersøkelse 160

Akutt urinveisinfeksjon

Residiverende urinveisinfeksjoner

Utredning for syndrom/

misdannelser

Magesmerter

Abdominalt palpasjonsfunn

$8 \quad(2)$

Familiær nyre-/urinveis-

anomali

Enuresis

3 (1)

Utredning for feber

Andre

17

Tabell 2 Forekomsten av ulike misdannelser i nyrer og urinveier hos 389 barn

\begin{tabular}{|lrr|}
\hline Type misdannelse & Antall & (\%) \\
\hline Hydronefrose & 235 & $(60)$ \\
\hline Vesikourethral reflux & 136 & $(35)$ \\
\hline Overgangsstenose & 66 & $(17)$ \\
\hline Hydroureter & 65 & $(17)$ \\
\hline Dobbelt ureter & 60 & $(15)$ \\
\hline Nyrecyster & 48 & $(12)$ \\
\hline Terminal ureterstenose & 21 & $(5)$ \\
\hline Bakre urethraklaffer & 18 & $(5)$ \\
\hline Nyreagenesi lensidig) & 16 & $(4)$ \\
\hline Ureterocele & 14 & $(4)$ \\
\hline Nyredysplasi & 11 & $(3)$ \\
\hline Ektopisk nyre & 7 & $(2)$ \\
\hline Polycystisk nyresykdom & 6 & $(2)$ \\
\hline Bilateral nyreagenesi & 6 & $(2)$ \\
\hline Meatus eksternus-stenose & 5 & $(1)$
\end{tabular}


Tabell 3 Dødsårsak hos 15 barn med misdannelser i nyrer og urinveier

Årsak

Antall

Bilateral nyreagenesi

(Potters syndrom)

Polycystisk nyresykdom

Hjertefeil/multicystisk nyre

Prematuritet/hjerneblødning/

hydronefrose

Nyresvikt/urethraklaffer

Sepsis/ensidig nyreagenesi

Akutt leukemi/sepsis/hydronefrose

nisk nyresvikt, døde eller gjennomgikk operasjon. Den økte andelen prenatalt diagnostiserte tilfeller, og trolig også bedret postnatal diagnostikk, har derfor ikke sikkert ledet til et målbart bedre resultat vurdert ut fra disse variablene. Små tall for disse endepunktene reduserer imidlertid den statistiske styrken i analysene. Tallene vil også påvirkes av endringer i indikasjonsstilling for operasjon og ev. bedret behandling.

Misdannelser i nyrer og urinveier er den hyppigste årsak til kronisk nyresvikt hos barn (19). I vårt materiale var disse pasientene relativt få (3\%). Dødeligheten var i samme størrelsesorden. De fleste dødsfall hadde sin årsak i alvorlige nyrelidelser, men så mange som en tredel skyldtes lidelser som ikke var relatert til nyre-/urinveismisdannelsen. Harris og medarbeidere fant $i$ en stor epidemiologisk undersøkelse langt høyere tall enn våre, men i deres studie inngikk kun de mer alvorlige diagnosene (15). Manglende malignitetsutvikling er i overensstemmelse med andre undersøkelser $(20,21)$. Mens man tidligere $\mathrm{i}$ stor grad nefrektomerte barn med multicystiske dysplastiske nyrer i frykt for hypertensjon og malignitetsutvikling, er trenden nå en mer konservativ oppfølging.

\section{Svakheter ved studien}

I vårt materiale har vi inkludert pasienter med koder for medfødte misdannelser i nyrer og urinveier i ICD-9 og ICD-10. Vi kan ha mistet pasienter med aktuelle misdannelser som har fått diagnoser som ikke omfattes

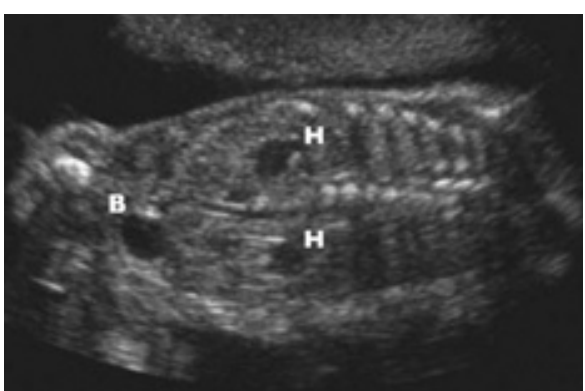

Figur 2 Lett dobbeltsidig hydronefrose hos foster (H). Merk fylling av urinblæren (B). Foto Lars Johansen, Kvinneklinikken, Sykehuset i Vestfold, Tønsberg av disse kodene. I materialet er data innhentet fra pasienter med alder på minst ett leveår på registreringstidspunktet. Noen av de yngste pasientene kan dermed bli diagnostisert med misdannelser etter registreringstidspunktet. Man kan også underestimere senkomplikasjoner og behov for behandling. Data fra pasientjournaler kan også være inkomplette. Våre tall må således betraktes som minimumstall.

Vårt materiale inneholder ikke opplysninger om målinger på prenatalt påvist hydronefrose eller utvikling av denne, da slike opplysninger hovedsakelig manglet $\mathrm{i}$ barnas journaler. Man trenger gode prospektive studier som inkluderer slike data, for bedre å kunne vurdere hvilke prenatale hydronefroser som trenger postnatal oppfølging, og hvordan denne skal gjøres.

\section{Konklusjoner}

Bedre prenatal diagnostikk (vesentlig av hydronefrose) har ført til $69 \%$ økning av prevalensen av misdannelser i nyrer og/eller urinveier. Den økte prevalensen har ikke ført til økt antall pasienter behandlet kirurgisk, eller endret forekomst av urosepsis, kronisk nyresvikt eller død i populasjonen. Med bakgrunn i mulig overdiagnostisering er det grunn til at man i et samarbeid mellom gynekologer, pediatere og kirurger, gjennomgår kriteriene for diagnosen prenatal hydronefrose, og oppfølgingen av denne.

Arbeidet er støttet av forskningsmidler fra Sykehuset $i$ Vestfold, Tønsberg.

Oppgitte interessekonflikter: Ingen

\section{Litteratur}

1. Queisser-Luft A, Stolz G. Wiesel A et al. Malformations in newborn: results based on 30,940 infants and fetuses from the Mainz congenital birth defect monitoring system (1990-1998). Arch Gynecol Obstet 2002: 266: 163-7.

2. Stoll C, Tenconi R, Clementi M. Detection of congenital anomalies by fetal ultrasonographic examination across Europe. Community Genet 2001; 4: 225-32.

3. Acton C, Pahuja M, Opie G et al. A 5-year audit of 778 neonatal renal scans (Part 1): perplexing pyelectasis and suggested protocol for investigation. Australas Radiol 2003; 47: 349-53.

4. Chitty LS, Hunt GH, Moore J et al. Effectiveness of routine ultrasonography in detecting fetal structural abnormalities in a low risk population. BMJ 1991; 303: 1165-9.

5. Smith D, Egginton JA, Brookfield DS. Detection of abnormality of fetal urinary tract as a predictor of renal tract disease. BMJ 1987; 294: 27-8.

6. Ek S, Lidefeldt KJ, Varricio L. Fetal hydronephrosis; prevalence, natural history and postnatal consequences in an unselected population. Acta Obstet Gynecol Scand 2007; 86: 1463-6.

7. Lee RS, Cendron M, Kinnamon DD et al. Antenatal hydronephrosis as a predictor of postnatal outcome: a meta-analysis. Pediatrics 2006; 118 : $586-93$.

8. Acton C, Pahuja M, Opie G et al. A 5-year audit of 778 neonatal renal scans (Part 2). Miscellaneous anomalies in 59 infants: a pictorial presentation. Australas Radiol 2003; 47: 354-62.

9. Refai Z, El-Rifai R. National audit of the management of antenatal renal pelvis dilatation. Arch Dis Child 2008; 93: 546.

10. Woodward M, Frank D. Postnatal management of antenatal hydronephrosis. BJU 2002; 89: 149-56.
11. Toiviainen-Salo S, Garel L, Grignon A et al. Fetal hydronephrosis: is there hope for consensus? Pediatr Radiol 2004; 34: 519-29.

12. de Kort EHM, Bambang Oetomo S, Zegers SHJ. The long-term outcome of antenatal hydronephrosis up to 15 millimetres justifies a noninvasive postnatal follow-up. Acta Paediatrica 2008; 97 : $708-13$.

13. Kase JS, Visintainer $P$. The relationship between congenital malformations and preterm birth. J Perinat Med 2007; 35: 538-42

14. Aksu N, Yava?can O, Kangin M et al. Postnatal management of infants with antenatally detected hydronephrosis. Pediatr Nephrol 2005: 20: 1253-9.

15. Harris J, Robert E, Källén B. Epidemiologic characteristics of kidney malformations. Eur J Perinatol 2000; 16: 985-92.

16. Avni EF, Schulman CC. The origin of vesico-ureteric reflux in male newborns: further evidence in favour of a transient fetal urethral obstruction. BJU 1996; 78: 454-9

17. Cocchi G, Magnani C, Morini MS et al. Urinary tract abnormalities (UTA) and associated malformations: data of the Emilia-Romagna Registry. IMER Group. Emilia-Romagna Registry on Congenital Malformations. Eur J Epidemiol 1996; 12: 493-7.

18. Ek S, Lidefeldt KJ, Varricio L. Fetal hydronephrosis; prevalence, natural history and postnatal consequences in an unselected population. Acta Obstet Gynecol Scand 2007; 86: 1463-6.

19. Woolf AS, Thiruchelvam N. Congenital obstructive uropathy: its origin and contribution to end-stage renal disease in children. Adv Ren Replace Ther 2001; 8: 157-63.

20. Homsy YL, Anderson JH, Oudjhane K et al. Wilms tumor and multicystic dysplastic kidney disease. J Urol 1997: 158: 2256-9.

21. Narchi H. Risk of Wilms' tumour with multicystic kidney disease: a systematic review. Arch Dis Child 2005; 90: 147-9.

Manuskriptet ble mottatt 26.8. 2008 og godkjent 20.5. 2009. Medisinsk redaktør Odd Terje Brustugun. 